\title{
TINGKAT RISIKO KONSTRUKSI DARI FAKTOR TENAGA KERJA, MATERIAL DAN PERALATAN PADA REKONSTRUKSI RUMAH PASCA BENCANA GEMPA DI KABUPATEN PIDIE JAYA
}

\author{
Firhan Ambiya ${ }^{1}$, Nurul Malahayati ${ }^{2}$, Nurisra ${ }^{3}$ \\ Jurusan Teknik Sipil, Fakultas Teknik, Universitas Syiah Kuala, Banda Aceh. \\ Email : ambiyafirhan@gmail.com
}

\begin{abstract}
Risks will always exist in the implementation of a construction project and can have a positive or negative impact on project performance and targets. In this study, the risks studied were construction risks with labor, material and equipment factors in the reconstruction of community-based houses after the earthquake disaster in Pidie Jaya Regency in 2016. The purpose of this study is to identify risk factors and analyze the level of construction risk on cost, quality and time. Data were collected using a questionnaire distributed to 30 qualified respondents as experts. The questionnaire instrument was tested using validity and reliability tests. The analysis used is the frequency index (FI), Severity index (SI), probability impact matrix (PIM). The results of this study are in the form of 30 potential risk variables from construction risk obtained by risk identification methods, interviews, questionnaires and instrument tests including 5 high-level risks that have an impact on time, there are 4 high-level risks that have an impact on costs and there are 6 high-level risks that have an impact on quality,
\end{abstract}

Keywords: risk, labor, materials, equipment, project targets, house reconstruction, post-disaster

\begin{abstract}
Abstrak
Risiko akan selalu ada dalam pelaksanaan sebuah proyek konstruksi dan dapat memiliki dampak positif maupun negatif bagi kinerja dan target proyek. Pada penelitian ini risiko yang diteliti adalah risiko konstruksi dengan faktor tenaga kerja, material dan peralatan yang terdapat pada rekonstruksi rumah berbasis masyarakat pasca bencana gempa bumi di Kabupaten Pidie Jaya pada tahun 2016. Tujuan dari penelitian ini adalah mengidentifikasi faktor-faktor risiko dan menganalisis tingkat risiko konstruksi terhadap biaya, mutu dan waktu. Data dikumpulkan menggunakan kuesioner yang disebarkan kepada 30 responden yang terkualifikasi sebagai tenaga ahli. Pengujian instrumen kuisioner dilakukan dengan uji validitas dan uji reliabilitas. Analisis yang digunakan adalah frequency index (FI), Severity index (SI), probability impact matrix (PIM). Hasil dari penelitian ini berupa 30 variabel risiko potensial dari risiko konstruksi yang didapatkan dengan metode identifikasi risiko, wawancara, kuesioner dan uji instrumen diantaranya terdapat 5 risiko tingkat tinggi yang berdampak terhadap waktu, 4 risiko tingkat tinggi yang berdampak terhadap biaya, dan terdapat 6 risiko tingkat tinggi yang berdampak terhadap mutu
\end{abstract}

Kata Kunci: risiko, tenaga kerja, material, peralatan, target proyek, rekonstruksi rumah, pasca benca

\section{Pendahuluan}

Aceh merupakan sebuah provinsi yang terletak di ujung utara Pulau Sumatera sekaligus menjadi wilayah paling barat di Indonesia. Letak geografis provinsi Aceh sangat berdekatan dengan lempeng Eurasia dan lempeng Indo-Australia yang mengakibatkan rawan terjadinya bencana alam seperti gempa bumi. Telah terjadi banyak gempa bumi yang signifikan di Provinsi Aceh salah satu contohnya adalah yaitu di Kabupaten Pidie Jaya. Gempa tersebut mengakibatkan sejumlah 16.238 rumah mengalami kerusakan yang diantaranya 2.536 rumah rusak berat, 2.473 rumah rusak sedang dan 11.329 rumah rusak ringan (JUKNIS, 2017). Kerusakan pada bangunanbangunan tersebut berdampak negatif terhadap pertumbuhan ekonomi, sosial dan hukum di Provinsi Aceh dikarenakan mayoritas kerusakan yang terjadi terdapat pada rumah masyarakat.

Menurut PMI (2017) risiko adalah peristiwa atau kondisi tidak pasti yang, jika terjadi, memiliki efek positif atau negatif pada satu atau lebih tujuan proyek. Risiko pada rekonstruksi dapat datang dari berbagai sumber namun pada penelitian ini berfokus yang bersumber dari risiko konstruksi. Dalam risiko konstruksi terdapat beberapa faktor yaitu tenaga kerja, 
material dan peralatan, Faktor-faktor tersebut merupakan bagian kritikal dari melaksanakan pekerjaan konstruksi sehingga jika pengendaliannya tidak sesuai maka akan mengakibatkan tidak tercapainya target proyek seperti biaya, mutu dan waktu. Dari latar belakang di atas, dilakukan penelitian yang bersifat kuantitatif yang memerlukan pengolahan data yang bersumber dari lokasi penelitian. Pengumpulan data di lapangan dilakukan dengan menggunakan metode checklist, wawancara, dan penyebaran kuesioner. Sementara untuk pengolahan data menggunakan metode uji statistika, analisis frequency index (FI), analisis Severity index (SI), dan analisis probability impact matrix (PIM).

a. Analisis Frequency Index (FI)

Untuk menghitung Analisis Frequency Index digunakan rumus pada persamaan (Well-Stam, et.al., $2004^{[6]}$ ) sebagai berikut :

$$
F I=\frac{\sum_{i=1}^{5} \alpha_{i} \cdot n_{i}}{5 N}
$$

Dimana:

$$
\begin{aligned}
\mathrm{i}= & \text { Indeks kategori respon. } \\
\alpha_{i}= & \text { Bobot yang dihubungkan dengan nilai } \\
& \text { respon ke-i. } \\
n_{i}= & \text { Frekuensi dari respon ke-i sebagai } \\
& \begin{array}{l}
\text { persentase dari total responden untuk } \\
\text { setiap faktor. }
\end{array} \\
\mathrm{N}= & \text { Total jumlah responden. }
\end{aligned}
$$

b. Analisa Severity Index (SI)

Untuk menghitung Analisis Severity Index digunakan rumus pada persamaan (Well-Stam, et.al., 2004 ${ }^{[6]}$ ) sebagai berikut:

$$
S I=\frac{\sum_{i=1}^{5} \alpha_{i} \cdot n_{i}}{5 N}
$$

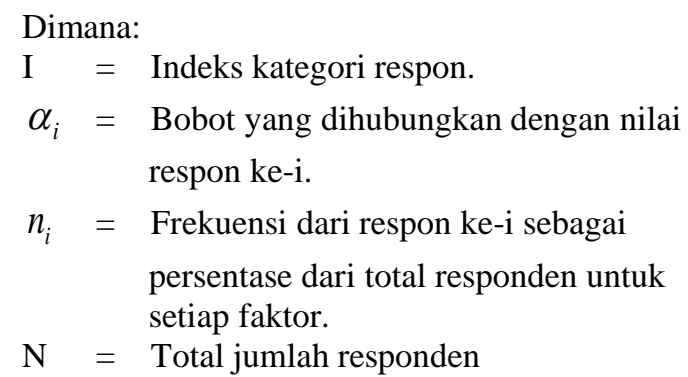

c. Probability Impact Matrix (PIM)

Untuk menghitung Probability Impact Matrix (PIM) digunakan rumus pada persamaan (WellStam, et.al., 2004 ${ }^{[6]}$ ) sebagai berikut:

$$
R=P \times I \quad \ldots \ldots 3)
$$

Dimana :

$\mathrm{R}=$ Tingkat risiko

$\mathrm{P}=$ Kemungkinan (probability) risiko yang terjadi

$\mathrm{I}=$ Dampak (impact) risiko yang terjadi

Adapun penelitian-penelitian yang telah dilakukan untuk mengetahui tingkat resiko konstruksi dari faktor tenaga kerja, material dan peralatan, diantaranya :

1. Ewelina dkk. (2011) melakukan penelitian dengan judul "Risk Management Practices in a Construction Project", mengunakan metode Studi literatur, case studi and interviews dengan hasil. Para profesional di industri konstruksi telah menggunakan manajemen risiko, tetapi tidak menyadarinya. Risiko dikelola setiap hari di industri, tetapi tidak dengan cara yang terstruktur. pengetahuan manajemen risiko dan praktik manajemen risiko mendekati nol, meskipun konsep manajemen risiko menjadi lebih populer di sektor konstruksi.

2. Rumimper dkk. (2015) melakukan penelitian dengan judul “Analisis Risiko pada Proyek Konstruksi Rumah di Kabupaten Minahasa Utara" mengunakan metode uji Validitas, uji rehabilitas, dan analisis komponen utama dengan hasil. Uji validitas, uji reliabilitas, dan analisis komponen utama Aspek utama pada proyek ini adalah aspek peralatan, kebijakan pemerintah, material, sumber daya manusia dan tenaga kerja, pengendalian, dan K3.

3. Saiful dkk. (2018) melakukan penelitian dengan judul "Risk Assessment of Resources Factor in Affecting Project Time" mengunakan metode Uji validitas, Uji reabilitas, Frequency Index (FI), Severity Index (SI), Risk Importance Index (RII) dengan hasil. Analisis data menggunakan metode FI, SI dan RII didapatkan risiko yang bersumber dari faktor tenaga kerja, 
material dan perlatan memiliki efek yang besar tehadap waktu penyelesaian proyek.

4. Novatus Senduk, dkk (2016) Risiko yang paling sering dihadapi oleh kontraktor yang menangani proyek yaitu kontrol kualitas bahan yang buruk dan kurangnya pengamanan di lokasi proyek

\section{Metodologi Penelitian}

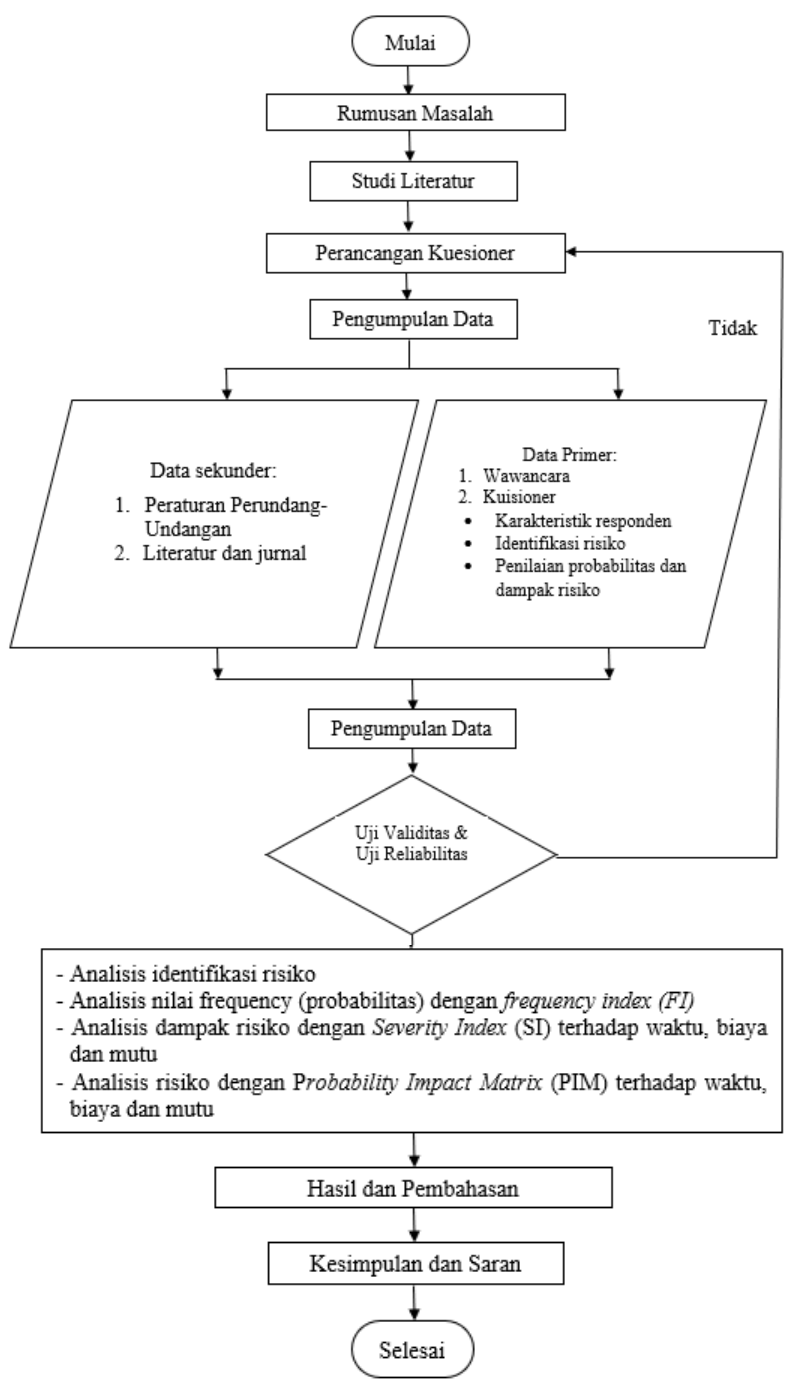

Gambar 2.1 Bagan Alir Penelitian

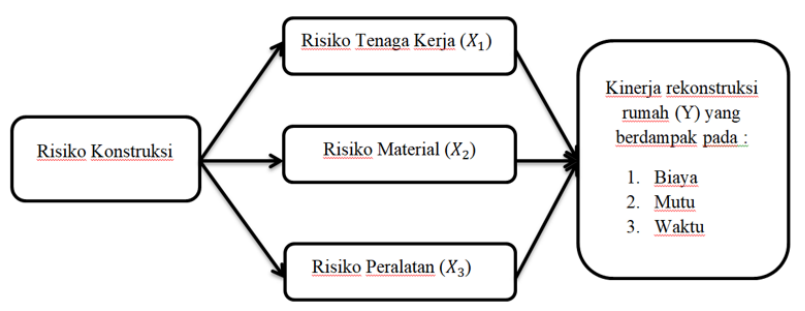

Gambar 2.2 Kerangka Konsep Penelitian

\section{Hasil}

Journal of The Civil Engineering Student

Vol. 3. No. 3, Desember 2021, Halaman 274-281
Hasil dari penelitian ini didapatkan dari pengumpulan data dan pengolahan data. Pengumpulan data yang dilakukan selama 2 bulan di Kabupaten Pidie Jaya berupa jawaban responden terhadap kuesioner identifikasi risiko dan penilaian probabilitas dan dampak risiko konstruksi. Jumlah narasumber untuk tahap identifikasi dan wawacara sebanyak 10 orang yang dipilih menggunakan teknik snowball sedangkan Responden dari kursioner berjumlah 30 orang yang sudah ditentukan disajikan di dalam bab ini adalah data karakteristik responden, uji validitas, uji reliabilitas, analisis Frequency Index (FI), analisis Severity Index (SI) dan analisi Probability Impact Matrix (PIM). Data tersebut diolah menggunakan software microsoft excel dan software Statistical Package for the Social Sciences (SPSS) 26 dengan uraian seperti tercantum di bawah ini.

1. Uji Validitas

Setiap pernyataan yang terdapat pada kuesioner dilakukan pengujian validitas baik itu probabilitas maupun dampak dari sebuah variabel risiko dan dibandingkan dengan $r_{\text {tabel }}$ dan pada tingkat signifikan yang diinginkan. Penelitian ini, tingkat signifikan yang diambil sebesar 5\%. Signifikan artinya meyakinkan atau berarti. Pengujian validitas dilakukan terhadap pihak responden secara kesuluruhan. dari 15 responden, sehingga nilai $\mathrm{r}_{\text {tabel }}$ untuk taraf signifikan 5\% diperoleh sebesar 0,514 . Hasil nilai $r$ yang telah didapatkan atau yang disebut juga dengan nilai $r_{\text {hitung }}$ dibandingkan dengan nilai $r_{\text {tabel }}$, dengan menggunakan kriteria $r_{\text {hitung }}>$ $\mathrm{r}_{\text {tabel }}$. maka instrumen atau item pernyataan berkorelasi signifikan terhadap skor total (dinyatakan valid). Perhitungan ini menggunakan rumus koefisien korelasi Pearson Product Moment, dibantu dengan (SPSS).

Tabel 3.1 Rekapitulasi hasil uji validitas tahap 1 
ISSN 2685-0605

\begin{tabular}{|c|c|c|c|c|}
\hline \multirow{2}{*}{$\begin{array}{c}\text { Kode } \\
\text { Kuesioner }\end{array}$} & Faktor Risiko & $\begin{array}{c}\text { Range Nilai } \\
\mathrm{r}_{\text {hitung }}\end{array}$ & \multirow{2}{*}{$\mathrm{r}_{\text {tabel }}$} & Ket \\
\cline { 3 - 3 } & $\begin{array}{c}\text { Probabilitas } \\
\text { Risiko }\end{array}$ & & \\
\hline TK1-W3 & Tenaga Kerja & $0,066-0,815$ & 0,514 & $\begin{array}{c}\text { Ada yang Tidak } \\
\text { Valid }\end{array}$ \\
\hline M1-W8 & Material & $0,139-0,743$ & 0,514 & $\begin{array}{c}\text { Ada yang Tidak } \\
\text { Valid }\end{array}$ \\
\hline P2-P20 & Peralatan & $0,030-0,915$ & 0,514 & $\begin{array}{c}\text { Ada yang Tidak } \\
\text { Valid }\end{array}$ \\
\hline
\end{tabular}

Dari Tabel 3.1 diatas dapat dilihat bahwa masih terdapat beberapa variabel risiko yang masih belum valid yaitu variabel dengan kode TK1, TK2, TK8, TK9, TK10, TK11, TK12, TK14, TK15, TK16, TK25, W3, M1, M4, M9, M15, M17, W6, W7, P7, P15, P16. Sehingga variabel-variabel tersebut dieliminasi dan dirancang kembali kuesionernya. Berikut merupakan rekapitulasi hasil uji validitas dari kuesioner yang telah dirancang kembali yang disajikan pada tabel 4.6 sebagai berikut :

Tabel 3.2 Rekapitulasi hasil uji validitas tahap 2

\begin{tabular}{|c|c|c|c|c|}
\hline \multirow{2}{*}{$\begin{array}{c}\text { Kode } \\
\text { Kuesioner }\end{array}$} & \multirow{2}{*}{ Faktor Risiko } & $\begin{array}{c}\text { Range Nilai } \\
\text { r }_{\text {hitung }}\end{array}$ & \multirow{2}{*}{$\mathrm{r}_{\text {tabel }}$} & \multirow{2}{*}{ Ket } \\
\cline { 3 - 4 } & $\begin{array}{c}\text { Probabilitas } \\
\text { Risiko }\end{array}$ & & \\
\hline TK3-W2 & Tenaga Kerja & $0,565-0,818$ & 0,514 & Valid \\
\hline M5-W8 & Material & $0,514-0,771$ & 0,514 & Valid \\
\hline P2-P20 & Peralatan & $0,660-0,940$ & 0,514 & Valid \\
\hline
\end{tabular}

Dari hasil rekapitulasi di atas dapat dilihat bahwa seluruh item dari kuesioner memiliki nilai $r_{\text {hitung }}$ lebih besar dari $r_{\text {tabel }}$. Sehingga kuesioner pada penelitian ini adalah valid dan dapat dilaksanakan prosess analisi selanjutnya.

2. Uji Reliabilitas.

Uji reliabilitas yang bertujuan untuk mengetahui tingkat keandalan instrumen penelitian sehingga alat ukur tetap konsisten jika dilakukan pengukuran di waktu yang berbeda. Perhitungan ini menggunakan rumus Cronbach Alpha. Nilai suatu variabel dikatakan reliable apabila nilai Cronbach Alpha melebihi nilai 0,6. Uji ini dilakukan dengan bantuan software Statistical Package for the Social Sciences (SPSS). Berikut merupakan rekapitulasi hasil uji Reliabilitas yang dapat dilihat pada Tabel 4.7.

Tabel 3.3 Rekapitulasi hasil uji reliabilitas

\begin{tabular}{|c|c|c|c|c|}
\hline \multirow{2}{*}{$\begin{array}{c}\text { Kode } \\
\text { Kuesioner }\end{array}$} & \multirow{2}{*}{ Faktor Risiko } & $\begin{array}{c}\text { Range Nilai C- } \\
\text { Alpha }\end{array}$ & \multirow{2}{*}{$\alpha$} & \multirow{2}{*}{ Ket } \\
\cline { 3 - 3 } & $\begin{array}{c}\text { Probabilitas } \\
\text { Risiko }\end{array}$ & & \\
\hline TK3-W2 & Tenaga Kerja & $0,961-0,963$ & 0,6 & Reliable \\
\hline M5-W8 & Material & $0,961-0,963$ & 0,6 & Reliable \\
\hline P2-P20 & Peralatan & $0,961-0,962$ & 0,6 & Reliable \\
\hline
\end{tabular}

Dari hasil rekapitulasi di atas dapat dilihat bahwa seluruh item variabel risiko memiliki nilai hitung $\mathrm{C}$ alpha lebih besar dari $\alpha$.

3. Analisis Frequency Index (FI)

Analisis Frequency Index (FI) memberikan indeks frekuensi kejadian (muncul) dan memberikan gambaran seberapa sering terjadi masing-masing item risiko atau variabel risiko di proyek rekonstruksi rumah pasca bencana di Kabupaten Pidie Jaya. Perhitungan freqeucy index dilakukan dengan bantuan microsoft excel, hasilnya diklasifikasi dan dinilai berdasarkan kriteria dari Riduwan (2007) dimana nantinya hasil dari klasifikasi dan penilaian nanti digunakan pada analisa matriks probabilitas dan dampak (PIM).

Tabel 3.4 Nilai analisa Frequency Index (FI)

\begin{tabular}{|c|c|c|c|c|c|}
\hline No. & Kode & $\begin{array}{l}\text { Dampak } \\
\text { Terhadap }\end{array}$ & Variabel & $\begin{array}{c}\text { Nilai } \\
\text { FI }\end{array}$ & Katagori \\
\hline 1 & TK3 & \multirow{6}{*}{$\begin{array}{c}\text { Faktor } \\
\text { Tenaga } \\
\text { Kerja } \\
\text { Faktor } \\
\text { Material }\end{array}$} & Tenaga kerja mogok kerja & 0,373 & Jarang \\
\hline 2 & TK5 & & $\begin{array}{l}\text { Motivasi dan semangat tenaga kerja } \\
\text { kurang }\end{array}$ & 0,433 & $\begin{array}{l}\text { Cukup } \\
\text { Sering }\end{array}$ \\
\hline 3 & TK7 & & $\begin{array}{l}\text { Penyakit yang menginfeksi tenaga } \\
\text { kerja }\end{array}$ & 0,400 & $\begin{array}{l}\text { Cukup } \\
\text { Sering }\end{array}$ \\
\hline 4 & TK18 & & $\begin{array}{l}\text { Kenaikan harga tenaga kerja yang } \\
\text { tidak diharapkan }\end{array}$ & 0,640 & Sering \\
\hline 5 & TK21 & & ketidakhadiran tenaga kerja & 0,447 & Jarang \\
\hline 6 & M5 & & Terjadinya pencurian material & 0,513 & $\begin{array}{l}\text { Cukup } \\
\text { Sering }\end{array}$ \\
\hline 7 & M6 & \multirow{6}{*}{$\begin{array}{l}\text { Biaya } \\
\text { Faktor } \\
\text { Peralatan }\end{array}$} & $\begin{array}{l}\text { Kualitas material tidak sesuai } \\
\text { spesifikasi }\end{array}$ & 0,547 & $\begin{array}{l}\text { Cukup } \\
\text { Sering }\end{array}$ \\
\hline 8 & M7 & & $\begin{array}{l}\text { Keterlambatan pengiriman material } \\
\text { ke lapangan }\end{array}$ & 0,673 & $\begin{array}{l}\text { Cukup } \\
\text { Sering }\end{array}$ \\
\hline 9 & M8 & & $\begin{array}{l}\text { Volume material tidak sesuai dengan } \\
\text { spesifikasi }\end{array}$ & 0,493 & $\begin{array}{l}\text { Cukup } \\
\text { Sering }\end{array}$ \\
\hline 10 & M10 & & Penggunaan material bekas & 0,587 & $\begin{array}{l}\text { Cukup } \\
\text { Sering }\end{array}$ \\
\hline 11 & P2 & & Peralatan tidak lengkap & 0,513 & $\begin{array}{l}\text { Cukup } \\
\text { Sering }\end{array}$ \\
\hline 12 & P3 & & $\begin{array}{l}\text { Peralatan tua harus segera di } \\
\text { modifikasi/diperbaiki untuk proyek }\end{array}$ & 0,513 & $\begin{array}{l}\text { Cukup } \\
\text { Sering }\end{array}$ \\
\hline 13 & P5 & \multirow{6}{*}{$\begin{array}{c}\text { Mutu } \\
\text { Faktor } \\
\text { Tenaga } \\
\text { Kerja }\end{array}$} & $\begin{array}{l}\text { Kerusakan alat saat pelaksanaan } \\
\text { proyek rekonstruksi }\end{array}$ & 0,480 & $\begin{array}{l}\text { Cukup } \\
\text { Sering }\end{array}$ \\
\hline 14 & P8 & & $\begin{array}{l}\text { Ketidaktelitian dalam pemeriksaan } \\
\text { kondisi peralatan }\end{array}$ & 0,360 & Jarang \\
\hline 15 & P9 & & Biaya tambahan sewa peralatan & 0,460 & $\begin{array}{l}\text { Cukup } \\
\text { Sering }\end{array}$ \\
\hline 1 & TK3 & & \begin{tabular}{|l|} 
Tenaga kerja mogok kerja \\
\end{tabular} & 0,373 & Jarang \\
\hline 2 & TK5 & & $\begin{array}{l}\text { Motivasi dan semangat tenaga kerja } \\
\text { kurang }\end{array}$ & 0,433 & $\begin{array}{l}\text { Cukup } \\
\text { Sering }\end{array}$ \\
\hline 3 & TK7 & & $\begin{array}{l}\text { Penyakit yang menginfeksi tenaga } \\
\text { kerja }\end{array}$ & 0,400 & $\begin{array}{l}\text { Cukup } \\
\text { Sering }\end{array}$ \\
\hline
\end{tabular}

Berdasarkan Tabel 3.4 contoh perhitungan Frequency Index (FI) pada risiko dengan kode TK3 yaitu "Tenaga kerja mogok kerja" diperoleh data sebagai berikut, 
yaitu 14 responden menyatakan bahwa probabilitas terjadinya desain tidak lengkap sangat jarang terjadi (SJ), 11 responden menyatakan jarang terjadi $(\mathrm{J}), 1$ responden menyatakan cukup sering terjadi (CS), 3 responden menyatakan sering terjadi (S) dan 1 orang responden menyatakan sangat sering terjadi (SS). Dilakukan perhitungan freqeucy index (FI) Nilai analisis Frequency Index (FI) yang didapatkan untuk variabel TK3 “Tenaga kerja mogok kerja" sebesar 0,373. Nilai Frequency Index (FI) tersebut dikonversikan terhadap skala penilaian probabilitas pada Tabel 3.4 dan didapat klasifikasinya adalah jarang (J) dengan skor 2.

4. Analisis Severity Index (SI)

Analisis severity index (SI) digunakan untuk pengolahan data dampak dari setiap risiko yang terdapat pada kuesioner penelitian. Nilai severity index (SI) menunjukkan indeks dampak tingkat pengaruh dari setiap faktor risiko terhadap biaya, mutu dan waktu pada proyek rekonstruksi rumah pasca bencana gempa bumi di Kabupaten Pidie Jaya. Tabel 3.5 yang terdapat dibawah ini menyajikan beberapa nilai hasil anailisi severity index (SI) pada risiko-risiko yang diteliti.

Tabel 3.5 Nilai Analisa Severity Index (SI)

\begin{tabular}{|c|c|c|c|c|c|}
\hline No. & Kode & $\begin{array}{l}\text { Dampak } \\
\text { Terhadap }\end{array}$ & Variabel & $\begin{array}{c}\text { Nilai } \\
\text { SI }\end{array}$ & Katagori \\
\hline 1 & TK3 & \multirow{6}{*}{ Waktu } & Tenaga kerja mogok kerja & 0,673 & Tinggi \\
\hline 2 & TK5 & & $\begin{array}{l}\text { Motivasi dan semangat tenaga kerja } \\
\text { kurang }\end{array}$ & 0,493 & Sedang \\
\hline 3 & M5 & & Terjadinya pencurian material & 0,593 & Sedang \\
\hline 4 & M6 & & $\begin{array}{l}\text { Kualitas material tidak sesuai } \\
\text { spesifikasi }\end{array}$ & 0,473 & Sedang \\
\hline 5 & $\mathrm{P} 2$ & & Peralatan tidak lengkap & 0,367 & Rendah \\
\hline 6 & P3 & & $\begin{array}{l}\text { Peralatan tua harus segera di } \\
\text { modifikasi/diperbaiki untuk proyek }\end{array}$ & 0,547 & Sedang \\
\hline 7 & TK3 & \multirow{6}{*}{ Biaya } & Tenaga kerja mogok kerja & 0,500 & Sedang \\
\hline 8 & TK5 & & $\begin{array}{l}\text { Motivasi dan semangat tenaga kerja } \\
\text { kurang }\end{array}$ & 0,560 & Sedang \\
\hline 9 & M5 & & Terjadinya pencurian material & 0,640 & Tinggi \\
\hline 10 & M6 & & $\begin{array}{l}\text { Kualitas material tidak sesuai } \\
\text { spesifikasi }\end{array}$ & 0,533 & Sedang \\
\hline 11 & $\mathrm{P} 2$ & & Peralatan tidak lengkap & 0,560 & Sedang \\
\hline 12 & P3 & & $\begin{array}{l}\text { Peralatan tua harus segera di } \\
\text { modifikasi/diperbaiki untuk proyek }\end{array}$ & 0,633 & Tinggi \\
\hline 13 & TK3 & \multirow{6}{*}{ Mutu } & Tenaga kerja mogok kerja & 0,360 & Rendah \\
\hline 14 & TK5 & & $\begin{array}{l}\text { Motivasi dan semangat tenaga kerja } \\
\text { kurang }\end{array}$ & 0,453 & Sedang \\
\hline 15 & M5 & & Terjadinya pencurian material & 0,440 & Sedang \\
\hline 16 & M6 & & $\begin{array}{l}\text { Kualitas material tidak sesuai } \\
\text { spesifikasi }\end{array}$ & 0,640 & Tinggi \\
\hline 17 & $\mathrm{P} 2$ & & Peralatan tidak lengkap & 0,460 & Sedang \\
\hline 18 & P3 & & $\begin{array}{l}\text { Peralatan tua harus segera di } \\
\text { modifikasi/diperbaiki untuk proyek }\end{array}$ & 0,640 & Tinggi \\
\hline
\end{tabular}

Berdasarkan Tabel 3.5 contoh perhitungan severity index (SI) pada risiko dengan kode TK3 yaitu "Tenaga kerja mogok kerja" didapat data sebagai berikut, yaitu 2 responden menyatakan bahwa dampaknya terhadap waktu adalah sangat rendah (SR), 3 responden menyatakan rendah $(\mathrm{R}), 11$ responden menyatakan sedang (S), 10 responden menyatakan tinggi (T) dan 4 responden menyatakan sangat tinggi (ST). Dilakukan perhitungan severity index (SI). Nilai analisis severity index (SI) yang didapatkan untuk TK3 “Tenaga kerja mogok kerja" sebesar 0,673. Nilai severity index (SI) tersebut dikonversikan terhadap skala penilaian probabilitas dan didapat klasifikasinya adalah tinggi (T) dengan skor 4.

\section{Probability Impact Matrix (PIM)}

Probability Impact Matrix (PIM) merupakan langkah terakhir dari metode analisis pada penelitian ini yang digunakan untuk menganalisis risiko secara kuantitatif dan memberikan tingkat prioritas kepada setiap risiko sehingga dapat diketahui risiko yang paling urgent untuk diperhatikan dan ditangani. Matriks yang digunakan yaitu matriks 5x5 dari PMI (2017). Matriks ini memiliki peringkat rendah, sedang, dan tinggi.

Hasil penyebaran kuesioner ke 30 responden ditemukan nilai probabilitas (P) dan dampak (I) setiap variabel risiko pada proyek rekonstruksi rumah pasca bencana gempa bumi di Kabupaten Pidie Jaya. Untuk mendapatkan nilai Probability Impact Matrix (PIM) adalah dengan mengalikan mengalikan kedua probabilitas risiko dan dampak risiko yang hasilnya diplotkan pada matrik, maka didapatkan tingkat risiko yang memudahkan untuk menilai mana risiko yang perlu diprioritaskan. Rekapitulasi tingkat risiko yang dianalisis menggunakan Probability Impact Matrix (PIM) terhadap waktu, biaya dan mutu dapat dilihat pada tabel di bawah ini:

Tabel 3.6 Tingkat risiko berdasarka (PIM) 
ISSN 2685-0605

\begin{tabular}{|c|c|c|c|c|c|}
\hline No. & Kode & $\begin{array}{l}\text { Dampak } \\
\text { Terhadap }\end{array}$ & Variabel & $\begin{array}{l}\text { Nilai } \\
\text { PIM }\end{array}$ & $\begin{array}{l}\text { Tingkat } \\
\text { Risiko }\end{array}$ \\
\hline 1 & TK3 & \multirow{6}{*}{ Waktu } & Tenaga kerja mogok kerja & 8 & SEDANG \\
\hline 2 & TK5 & & $\begin{array}{l}\text { Motivasi dan semangat tenaga kerja } \\
\text { kurang }\end{array}$ & 9 & SEDANG \\
\hline 3 & M5 & & Terjadinya pencurian material & 9 & SEDANG \\
\hline 4 & M6 & & $\begin{array}{l}\text { Kualitas material tidak sesuai } \\
\text { spesifikasi }\end{array}$ & 9 & SEDANG \\
\hline 5 & $\mathrm{P} 2$ & & Peralatan tidak lengkap & 6 & RENDAH \\
\hline 6 & P3 & & $\begin{array}{l}\text { Peralatan tua harus segera di } \\
\text { modifikasi/diperbaiki untuk provek }\end{array}$ & 9 & SEDANG \\
\hline 7 & TK3 & \multirow{6}{*}{ Biaya } & Tenaga kerja mogok kerja & 6 & SEDANG \\
\hline 8 & TK5 & & $\begin{array}{l}\text { Motivasi dan semangat tenaga kerja } \\
\text { kurang }\end{array}$ & 9 & SEDANG \\
\hline 9 & M5 & & Terjadinya pencurian material & 12 & TINGGI \\
\hline 10 & M6 & & $\begin{array}{l}\text { Kualitas material tidak sesuai } \\
\text { spesifikasi }\end{array}$ & 9 & SEDANG \\
\hline 11 & $\mathrm{P} 2$ & & Peralatan tidak lengkap & 9 & SEDANG \\
\hline 12 & P3 & & $\begin{array}{l}\text { Peralatan tua harus segera di } \\
\text { modifikasi/diperbaiki untuk proyek }\end{array}$ & 12 & IGGI \\
\hline 13 & TK3 & \multirow{6}{*}{ Mutu } & Tenaga kerja mogok kerja & 4 & RENDAH \\
\hline 14 & TK5 & & $\begin{array}{l}\text { Motivasi dan semangat tenaga kerja } \\
\text { kurang }\end{array}$ & 9 & SEDANG \\
\hline 15 & M5 & & Terjadinya pencurian material & 6 & RENDAH \\
\hline 16 & M6 & & $\begin{array}{l}\text { Kualitas material tidak sesuai } \\
\text { spesifikasi }\end{array}$ & 12 & TINGGI \\
\hline 17 & P2 & & Peralatan tidak lengkap & 9 & SEDANG \\
\hline 18 & P3 & & $\begin{array}{l}\text { Peralatan tua harus segera di } \\
\text { modifikasi/diperbaiki untuk proyek }\end{array}$ & 12 & TINGGI \\
\hline
\end{tabular}

\section{Pembahasan}

Pengumpulan data dilakukan dengan menggunakan metode identifikasi risiko dan wawancara terhadap tenaga ahli. Metode ini dilakukan karena menurut PMI 2017 salah satu tahap pada manajemen risiko adalah tahap identifikasi risiko. Penentuan narasumber dilakukan menggunakan metode snowball yang diawali dengan menjumpai Kepala BPBD Kabupaten Pidie Jaya sekaligus sebagai narasumber. Wawancara dilanjutkan kepada responden lain yang ditunjuk langsung oleh Kepala BPBD, yaitu fasilitator dan POKMAS. Narasumber yang dipilih merupakan tenaga ahli yang langsung terlibat dalam pelaksanaan rekonstruksi di Kabupaten Pidie Jaya.

Hasil dari identifikasi risiko ditemukan sebanyak 44 variabel risiko yang dibagi menjadi 3 kategori faktor yaitu: faktor tenaga kerja dengan jumlah risiko sebanyak 18 variabel, faktor material dengan jumlah risiko sebanyak 13 variabel dan faktor peralatan dengan jumlah risiko 13 variabel. untuk hasil tahap wawancara digunakan untuk mendapatkan masukan risiko tambahan dari para ahli terhadap faktor tenaga kerja dengan jumlah 3 variabel, material dengan jumlah 5 variabel, sementara peralatan tidak dijumpai variabel tambahan.

Tabel 4.1 Rincian Hasil Identifikasi Risiko

\begin{tabular}{|c|c|c|}
\hline Sumber Risiko & Faktor Risiko & $\begin{array}{c}\text { Risiko } \\
\text { Teridentifikasi }\end{array}$ \\
\hline \multirow{3}{*}{ Risiko Konstruksi } & Faktor Tenaga Kerja & 18 \\
\cline { 2 - 3 } & Faktor Material & 13 \\
\cline { 2 - 3 } & Faktor Peralatan & 13 \\
\hline \multirow{2}{*}{$\begin{array}{c}\text { Risiko Konstruksi } \\
\text { Hasil Wawancara }\end{array}$} & Faktor Tenaga Kerja & 3 \\
\cline { 2 - 3 } & Faktor Material & 5 \\
\hline \multicolumn{2}{|c|}{ Jumlah } & 52 \\
\hline
\end{tabular}

Setelah seluruh variabel risiko di kuesioner telah dianggap valid dan reliable, dilanjutkan dengan analisis Frequency Index (FI) untuk mendapatkan probabilitas terjadinya risiko dan severity index (SI) untuk mendapatkan seberapa besar dampak risiko terhadap waktu, biaya dan mutu. Hasil dari nilai Frequency Index (FI) dan severity index (SI) sangat bervariasi yang bergantung pada jawaban responden, yang dimana dikonversikan kedalam skor klasifikasi dan skala penelitian. Selanjutnya dilakukan perhitungan analisis probability impact matrix (PIM) untuk mendapatkan tingkat dari setiap variabel risiko dengan menggunakan perkalian antara data probabilitas terjadinya risiko dan dampak terhadap waktu, biaya, dan mutu lalu diplotkan ke dalam matriks probabilitas dan dampak risiko Untuk lebih jelasnya, tingkat risiko dari dampak terhadap waktu, biaya dan mutu pelaksanaan rekonstruksi bencana gempa bumi Kabupaten Pidie Jaya dapat dilihat pada grafik dibawah ini.

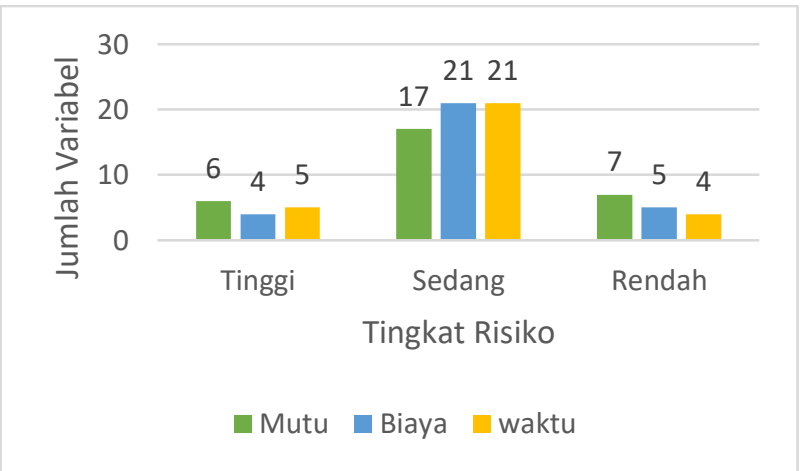

Gambar 4.1 Nilai tingkat risiko pada faktor ketiga

Berdasarkan Grafik 4.1 di atas dapat disimpulkan bahwa terdapat nilai tingkat risiko yang sangat bervariasi dari hasil Perhitungan probability impact matrix (PIM) diantaranya kategori risiko tingkat tinggi (high risk), risiko tingkat sedang (medium risk), dan risiko tingkat rendah (low risk). Tabel 4.12 dibawah merupakan rincian 
variabel-variabel risiko yang memiliki kategori tingkat risiko tinggi (high risk).

Tabel 4.2 Rincian Risiko Tingkat Tinggi (high risk)

\begin{tabular}{|c|c|c|c|c|}
\hline No. & $\begin{array}{l}\text { Dampak } \\
\text { Terhadap }\end{array}$ & Kode & Variabel & Tingkat Risiko \\
\hline 1 & \multirow{5}{*}{ Waktu } & M7 & $\begin{array}{l}\text { Keterlambatan pengiriman material ke } \\
\text { lapangan }\end{array}$ & TINGGI \\
\hline 2 & & M18 & $\begin{array}{l}\text { Manajemen \& perencanan material yang } \\
\text { buruk }\end{array}$ & TINGGI \\
\hline 3 & & TK7 & Penyakit yang menginfeksi tenaga kerja & TINGGI \\
\hline 4 & & P5 & $\begin{array}{l}\text { Kerusakan alat saat pelaksanaan proyek } \\
\text { rekonstruksi }\end{array}$ & TINGGI \\
\hline 5 & & P20 & $\begin{array}{l}\text { Manajemen \& perencanaan peralatan yang } \\
\text { buruk }\end{array}$ & TINGGI \\
\hline 6 & \multirow{4}{*}{ Biaya } & TK18 & $\begin{array}{l}\text { Kenaikan harga tenaga kerja yang tidak } \\
\text { diharapkan }\end{array}$ & TINGGI \\
\hline 7 & & M5 & Terjadinya pencurian material & TINGGI \\
\hline 8 & & W4 & $\begin{array}{l}\text { Cuaca yang tidak mendukung merusak } \\
\text { mutu material }\end{array}$ & TINGGI \\
\hline 9 & & P3 & $\begin{array}{l}\text { Peralatan tua harus segera di } \\
\text { modifikasi/diperbaiki untuk proyek }\end{array}$ & TINGGI \\
\hline 10 & \multirow{6}{*}{ Mutu } & TK26 & Pengawasan tenaga kerja yang buruk & TINGGI \\
\hline 11 & & TK24 & $\begin{array}{l}\text { Pemahaman spesifikasi pekerjaan yang } \\
\text { tidak sama. }\end{array}$ & TINGGI \\
\hline 12 & & M6 & Kualitas material tidak sesuai spesifikasi & TINGGI \\
\hline 13 & & M8 & $\begin{array}{l}\text { Volume material tidak sesuai dengan } \\
\text { spesifikasi }\end{array}$ & TINGGI \\
\hline 14 & & M10 & Penggunaan material bekas & TINGGI \\
\hline 15 & & $\mathrm{P} 3$ & $\begin{array}{l}\text { Peralatan tua harus segera di } \\
\text { modifikasi/diperbaiki untuk proyek }\end{array}$ & TINGGI \\
\hline
\end{tabular}

\section{Kesimpulan}

1. Hasil analisis Probability and Impact Matrix (PIM) ditemukan risiko yang memiliki dampak terhadap waktu sejumlah 5 variabel risiko dengan nilai risiko tinggi (high risk), 21 variabel risiko dengan nilai sedang (medium risk), 4 variabel risiko dengan nilai rendah (low risk). Sementara itu, dampak terhadap biaya sejumlah 4 variabel risiko dengan nilai tinggi (high risk), 21 variabel risiko dengan nilai sedang (medium risk), 5 variabel risiko dengan nilai rendah (low risk) dan dampak terhadap mutu sejumlah 6 variabel risiko dengan nilai tinggi (high risk), 17 variabel risiko dengan nilai sedang (medium risk), 7 variabel risiko yang dengan rendah (low risk).

2. Hasil dari analisis Probability and Impact Matrix (PIM) menunjukkan bahwa faktor risiko yang memiliki dampak yang besar terhadap waktu adalah faktor material dan peralatan. Sedangkan faktor risiko yang berdampak besar terhadap biaya dan mutu adalah faktor material.

\section{Saran}

1. untuk pemangku kepentingan dalam pelaksanaan program rehabilitasi dan rekonstruksi pasca bencana mendapatkan referensi untuk melakukan praktik manajemen risiko dari hasil identifikasi dan analisa penelitian ini, sehingga dapat mengurangi probabilitas dan dampak risiko terhadap waktu, biaya dan mutu pelaksanaan program rehabilitasi dan rekonstruksi kedepannya.

2. Kepada penelitan berikutnya dapat mengkaji faktor desain, internal, external dan faktor lainnya yang berhubungan dalam pelakasanaan program rehabilitasi dan rekonstruksi rumah pasca bencana gempa di Kabupaten Pidie Jaya.

\section{Daftar Pustaka}

[1] Adi, Isbandi Rukminto. 2001. Pemberdayaan, Pengembangan Masyarakat dan Intervensi Komunitas (Pengantar Pada Pemikiran dan Pendekatan Praktis), Lembaga Penerbit Fakultas Ekonomi Universitas Indonesia: Jakarta.

[2] BPBD. 2017. Petunjuk Teknis Rehabilitasi dan Rekonstruksi Sektor Permukiman Berbasis Masyarakat (Insitu) Pasca bencana Gempa Bumi di Kabupaten Pidie Jaya. BPBD. Jakarta.

[3] Gajewska, E., \& Ropel, M. 2011. Risk Management Practices in a Construction Project-a case study. Chalmers University of Technology. Swedia.

[4] Hillson,D , 2002. Effective Opportunity Managment for Projects, Marcel Dekker,Inc, New York.

[5] Husin, S., Abdullah, A., Riza, M., \& Afifuddin, M. 2018. Risk assessment of resources factor in affecting project time.Advances in Civil Engineering, Banda Aceh.

[6] Well-Stam, D Van, et.al., ProjectRisk Management: anessentialtool for managing andcontrolling project, Kogan Page, London a nd Sterling VA, 2004

[7] Isbandi Rukminto Adi. 2007. Perencanaan Partisipatoris Berbasis Aset Komunitas: dari Pemikiran Menuju Penerapan, Depok: FISIP IU Press. Jakarta. 
[8] Kerzner, H. R. 2013. Project management: a systems approach to planning, scheduling, and controlling. John Wiley \& Sons. New York.

[9] Kerzener, H. 2009. Project Management: A System Aproach to Planning, Scheduling and Controling. John Wiley \& Sons, Inc. New York.

[10] Larson, E. W., \& Gray, C. F. 2015. A guide to the project management body of knowledge: PMI (®) guide. In Project Management Institute (Vol. 1095).
[11] Tejakusuma, I. G. (2008). Analisis Pasca Bencana Tsunami Ciamis-Cilacap. Jurnal Sains dan Teknologi Indonesia, 10(2). Jakarta.

[12] Syamsidik, Nugroho, A., Oktari, R. S., \& Fahmi, M. (2019). Aceh Pasca Lima Belas Tahun Tsunami: Kilas Balik dan Proses Pemulihan. Banda Aceh, Aceh, Indonesia: Tsunami and Disaster Mitigation Reseacrh Center (TDMRC) Universitas Syiah Kuala.

[13] Aquilone, M. 2017. A Review on the Role of Project Management in Disaster Management. Disaster Management. 